\title{
Histopathological features of endometrium in those with symptoms suggestive of female genital tuberculosis
}

\author{
Sankareswari R., Arthy S.*
}

Department of Obstetrics and Gynecology, Sri Venkateshwaraa Medical College Hospital and Research Centre, Ariyur, Pondicherry, India

Received: 21 June 2018

Accepted: 24 July 2018

*Correspondence:

Dr. Arthy S.,

E-mail: drarthymsog@gmail.com

Copyright: (c) the author(s), publisher and licensee Medip Academy. This is an open-access article distributed under the terms of the Creative Commons Attribution Non-Commercial License, which permits unrestricted non-commercial use, distribution, and reproduction in any medium, provided the original work is properly cited.

\section{ABSTRACT}

Background: Genital tuberculosis is an important cause of female infertility. It is estimated that 5-13 percent of females presenting themselves in infertility clinics in India have genital tuberculosis. Objective of present study was to compare the prevalence of symptoms suggestive of genital tuberculosis between the patients suffering from infertility and the patients with normal fertility.

Methods: A random of 200 female OPD patients who were proved to be negative for genital TB (FGTB) by Microscopy, AFB culture, AFB-PCR and histopathology were retrospectively analyzed for presence of symptoms suggestive of FGTB. A comparative study was done to find any specific association of symptoms suggestive of FGTB with infertility.

Results: Oligomenorrhoea was the only symptom significantly $(\mathrm{p}=0.02)$ associated with those suffering from infertility $[n=64(32 \%)]$. The rest of the symptoms suggestive of FGTB were not significantly associated with infertility.

Conclusions: Symptoms suggestive of FGTB are present even in those who are proved Negative for FGTB and nonsignificantly associated with those with infertility in whom FGTB is expected to be an important cause. This paradox questions the specificity of these symptoms in developing a symptomatic diagnostic algorithm for FGTB.

Keywords: Female genital tuberculosis, Infertility, Oligomenorrhoea

\section{INTRODUCTION}

The prevalence of genital tuberculosis is largely underestimated. In developed countries, such as USA, Australia and Western European countries, the incidence of genital tuberculosis (GTB) is less than $1 \%$ but the incidence in some African countries is as high as 15$19 \% .^{1-3}$

Various Indian studies have shown that tuberculous endometritis and salpingitis account for 4-9 percent of all infertility cases. ${ }^{4-7}$ In India the incidence of genital tuberculosis is nearly about $18 \% .^{8}$ It is estimated that $1 \%$ of infertile women, aged between 20-40 years in United States and $18 \%$ in India suffer from genital TB. ${ }^{9}$ FGTB can present with varied symptoms such as vague abdominal pain, dysmenorrhea, oligomenorrhoea, amenorrhoea, infertility, menorrhagia, vaginal discharge, dyspareunia, post-coital bleeding and abdominal swelling, but most of the cases are asymptomatic. Female Genital tuberculosis (FGTB) is estimated to be prevalent in 5-13 per cent of females. ${ }^{10}$ Presenting themselves in infertility clinics in India. ${ }^{1}$ It is typically understood as a disease of young women, with $80 \%$ to $90 \%$ of cases diagnosed in patients $20 \pm 40$ years old, often During workup for infertility. ${ }^{2,11}$ 
Genital tract TB is a chronic disease that often presents with low grade varying symptomatology; infertility being the most frequent clinical presentation (43-74\%). Other clinical presentations include oligomenorrhoea (54\%) abdominal pain $(42.5 \%)$, amenorrhea (14\%), menorrhagia $(19 \%)$, dysmenorrhea (12-30\%) and dyspareunia (5$12 \%) .^{3,12}$

While evaluating for infertility, even though FGTB is an important differential diagnosis, it is very difficult to diagnose FGTB owing to lack of specific symptoms associated. Hence an attempt was made to find out the association of symptoms suggestive of FGTB with infertility.

\section{METHODS}

This study was conducted at Sri Venketeshwara Medical College, Hospital and Research centre, Ariyur, Puducherry between January to June 2015 for 200 patients with suggestive symptoms of genital tuberculosis attending to the gynaecology OPD in department of Obstretics and Gynaecology. Inclusion criteria were, Infertility-primary or secondary, Menstrual disturbancesamenorrhea, dysmenorrhea, oligomenorrhoea, menorrhagia, vague abdominal pain of one month duration and more, vaginal discharge, general malaise, abdominal mass, loss of weight and appetite, fever, cough with or without expectoration. Exclusion criteria were, acute abdominal pain, patients not willing for endometrial biopsy, unmarried women. An initial interview about demographic details and symptoms suggestive of genital TB was carried out at the OPD followed by clinical examination. The included subjects were then subjected to basic laboratory investigations routine blood examinations like haemoglobin estimation, Total leucocyte count, Differential count, Mantoux test, chest X-ray, sputum AFB (in patients with cough with expectoration), Ultrasound abdomen and pelvis, urine routine, HIV screening (after obtaining informed consent of both the patient and her spouse-according to standard guidelines), gram stain and culture-vaginal discharge, PAP smear, followed by an endometrial curettage. Endometrial Curettage was done using pipelle endometrial curette under aseptic precautions (between Day 15-Day 25 of the menstrual cycle). It was crosschecked with ultra-sonogram to ensure all included subjects had an endometrial thickness of $10 \mathrm{~mm}$ or more. Laparoscopy was done in indicated cases to rule out other genital pathologies. All patients included in the study were evaluated by our hospital pulmonologist to rule out co-existing active or old healed pulmonary TB. Clinical examination was followed by Tuberculin (Mantoux) skin testing, Sputum AFB examination (only in patients with cough with expectoration) and Chest X-ray. All the 200 participants were proved negative for FGTB by confirmatory tests. A comparative analysis was made retrospectively to find the association of symptoms suggestive of FGTB with infertility.

\section{Statistical analysis}

SPSS version -20 was used for statistical analysis and calculated frequency, percentages, mean, SD and median. As a descriptive statistics for inference to compare the difference between quantitative variables we used independent $\mathrm{T}$-test, to compare qualitative variable we used chi-square test at $5 \%$ level of significance.

\section{RESULTS}

Majority (94.5\%) (Figure 1) of the subjects belonged to the age group of 21 to 40 years coming from Pondicherry (38.5\%), Villupuram (36.5\%) and Cuddalore (19\%).

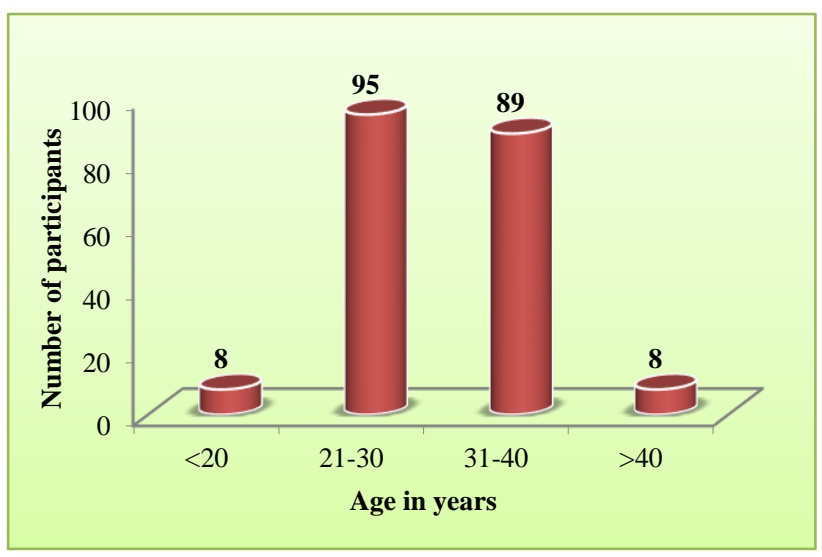

Figure 1: Age distribution of the study participants.

Half of the study participants (52\%) (Figure 2) belonged to Class III Socio-economic status, majority of them $(76.5 \%)$ being home-makers and educated upto high school level (46.5\%).

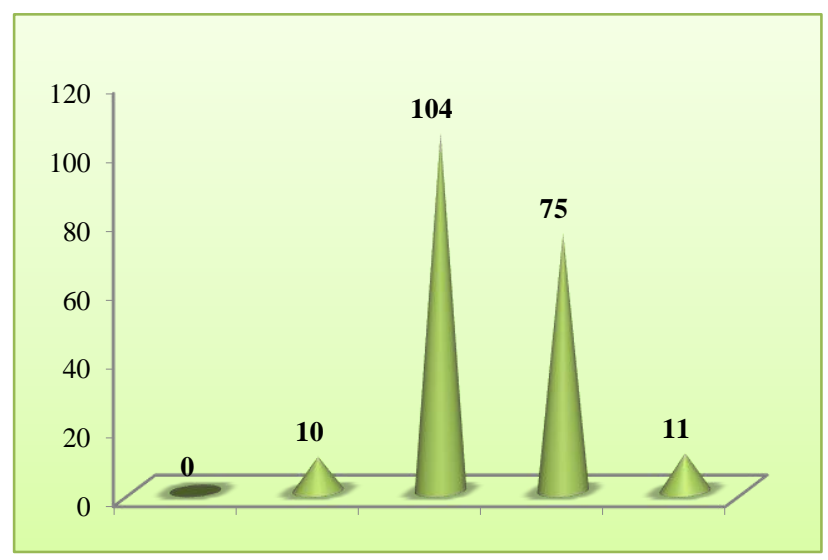

Figure 2: Distribution of the study participants according to their SES.

Only $5(2.5 \%)$ subjects had previous history of treatment for TB. Of the symptoms suggestive of FGTB, vaginal discharge was reported by $50.5 \%$ of the women interviewed. Menorrhagia (25\%), infertility (32\%), amenorrhoea, (8.5\%), oligomenorrhoea (24\%), hypomenorrhoea, (16.5\%), dysmenorrhoea (32.5\%), 
abdominal pain $(35.5 \%)$, malaise $(9.5 \%)$, loss of weight $(10 \%)$, loss of appetite $(8.5 \%)$, fever $(3 \%)$, cough $(4.5 \%)$ were the other suggestive symptoms identified among the participants. On retrospective analysis of symptoms of FGTB associated with Infertility, oligomenorrhoea was the only symptom significantly $(\mathrm{p}=0.02)$ associated with those suffering from infertility $[\mathrm{n}=64(32 \%)]$. The rest of the symptoms suggestive of FGTB were not significantly associated with infertility (Table 1).

Table 1: Symptoms suggestive of FGTB associated with infertility.

\begin{tabular}{|llll|}
\hline & $\begin{array}{l}\text { Infertility } \\
(\%)\end{array}$ & $\begin{array}{l}\text { Normal } \\
\text { fertility }(\%)\end{array}$ & $\begin{array}{l}\text { P } \\
\text { value* }\end{array}$ \\
\hline $\begin{array}{l}\text { Family History; } \\
\text { TB }\end{array}$ & $4(6.3)$ & $10(7.4)$ & 0.78 \\
\hline $\begin{array}{l}\text { Oligomenorrhea } \\
\text { Amennorhea }\end{array}$ & $6(32.8)$ & $25(18.4)$ & 0.02 \\
\hline Hypomenorrhea & $3(4.7)$ & $12(8.8)$ & 0.9 \\
\hline Menorrhagia & $10(15.6)$ & $40(29.4)$ & 0.03 \\
\hline Dysmenorrhoea & $13(20.3)$ & $52(38.2)$ & 0.01 \\
\hline $\begin{array}{l}\text { Vaginal } \\
\text { discharge }\end{array}$ & $14(21.9)$ & $88(64.7)$ & $<0.001$ \\
\hline Loss of appetite & $1(1.6)$ & $16(11.8)$ & 0.015 \\
\hline Loss of weight & $2(3.1)$ & $18(13.2)$ & 0.02 \\
\hline Fever & $0(0)$ & $6(4.4)$ & 0.08 \\
\hline Cough & $1(1.6)$ & $9(6.6)$ & 0.12 \\
\hline Total & $64(32)$ & $136(68)$ & \\
\hline *Chi square test/ FLVKUV Exact test & \\
\hline
\end{tabular}

\section{DISCUSSION}

Infertility appears to be the most common initial symptom for FGTB in $40 \pm 50 \%$ of patients in various studies done elsewhere. ${ }^{13-15}$ In the present study infertility was associated with $32 \%(n=64)$ of the study participants. Infertility when associated with other suggestive symptoms of FGTB should increase the suspicion of FGTB. But the symptoms are never specific as expected. To further enlighten this fact, a group of 200 patients who were proved negative for FGTB on confirmatory tests were retrospectively analysed for the association of symptoms with infertility. Except for Oligomenorrhoea, other common suggestive symptoms including vaginal discharge $\quad(p<0.001)$, hypomenorrhoea $\quad(p=0.002)$, menorrhagia $(\mathrm{p}=0.03)$, dysmenorrhea $(\mathrm{p}=0.01)$, etc $($ Table 1) were associated significantly with the normally fertile patients. In a study by Sri et al, out of the total 100 cases, 83 had primary infertility and 17 had secondary infertility. The follow up study showed only $12 \%$ incidence of FGTB among the infertility cases. ${ }^{1}$ In the present study, $26.5 \% \quad(n=53)$ had history of primary infertility and $5.5 \%(\mathrm{n}=11)$ had secondary infertility. But none of the cases had FGTB. This shows the essentiality of awareness and readiness to evaluate asymptomatic cases of FGTB among infertility patients. Chavan PV et al in their study about awareness about RNTCP and DOTS among health professionals found very low awareness $(28 \%)$ among the Medical professionals. ${ }^{17}$ The awareness regarding extra-pulmonary forms of TB has to be increased as it requires a high index of suspicion to pick up asymptomatic FGTB cases and having proved the non-specific association of suggestive symptoms of FGTB with infertility, the task becomes further herculean.

\section{CONCLUSION}

The study clearly showed that in infertility cases, suggestive symptoms of FGTB showed no significant association. Further as a paradox, none of the cases of infertility were positive for FGTB on confirmation. Hence the symptoms suggestive of FGTB cannot be used as a clue for diagnosis of FGTB as they were proved nonspecific. This study also proved the essentiality of confirmatory laboratory/ diagnostic imaging methods in ruling out FGTB in infertility patients even though they were asymptomatic.

\section{Funding: No funding sources}

Conflict of interest: None declared

Ethical approval: The study was approved by the Institutional Ethics Committee

\section{REFERENCES}

1. Dhillon SS, Gosewehr JA, Julian TM, Huey J. Genital tuberculosis: Case report and literature review. WMJ. 1990;89:14

2. Schaefer G. Female genital tuberculosis. Clin Obstet Gynecol. 1976;19:223.

3. American Thoracic Society. Diagnostic standards and classification of tuberculosis. Am Rev Respir Dis. 1990;142:72-35.

4. Goldin AG, Baker WT. Tuberculosis of the female genital tract. J Ky Med Assoc. 1985;83:75.

5. Varma TR. Genital tuberculosis and subsequent fertility. Int J Gynaecol Obstet. 1991;35:1.

6. Klein TA, Richmond JA, Mishell DR. Pelvic tuberculosis. Obstet Gynecol. 1976;48:99.

7. Tripathy SN, Tripathy SN. Endometrial tuberculosis. J Indian Med Assoc. 1987;85:136.

8. Marjorie PG, Holenarasipur RV. Extra pulmonary tuberculosis: An overview. Am Fam Physician. 2005;72:1761-8.

9. Vithalani N, Udani PM, Vithalani N. A study of 292 autopsies proved cases of tuberculosis. Indian $\mathbf{J}$ Tuber. 1982;29:93-7.

10. Parikh FR, Nadkarni SG, Kamat SA, Naik N, Soonawala SB, Parikh R, et al. Genital tuberculosis a major pelvic factor causing infertility in Indian women. Fertil Steril. 1997;67:497-9.

11. Schaefer G. Female genital tuberculosis. Clin Obstet Gynecol. 1976;19:223.

12. Gatongi DK, Gitau G, Kay V, Ngwenya S, Lafong C, Hasan A. Female genital tract tuberculosis. Obstet Gynaecol. 2005;7:75-9. 
13. Punnonen R, Kilholma P, Meurman L. Female genital tuberculosis and consequent infertility. Int $\mathrm{J}$ Fertil. 1983;28:235.

14. Francis WJA. Female genital tuberculosis. J Obstet Gynaecol Br Commonw. 1964;71:418

15. Russel PMG, Jackson MH, Midgley RL. A personal study of forty cases of pelvic tuberculosis. J Obstet Gynaecol Br Emp. 1951;58:712.

16. Sri S, Khannum N, Padmaja P, Taraporewalla FN Prevalence of endometrial tuberculosis in infertility cases. Int J Sci Res. 2015 Jun;4(6):278-9.
17. Chavan PV, Datta D, Patil RS, Arun DJ. Awareness about RNTCP and DOTS guidelines among health care professionals of a tertiary care hospital of South India. National J Comm Med 2014;5(1):77-80.

Cite this article as: Sankareswari R, Arthy S. Histopathological features of endometrium in those with symptoms suggestive of female genital tuberculosis. Int J Reprod Contracept Obstet Gynecol 2018;7:3649-52. 